Service social

\title{
Réussir sa jeunesse - Réflexions du Congrès international sur la jeunesse, textes choisis et présentés par Simone Piuze, Montréal, Stanké, 1986, 162 pages.
}

\section{Jocelyn Lindsay}

Volume 35, numéro 3, 1986

Les jeunes et le travail social

URI : https://id.erudit.org/iderudit/706332ar

DOI : https://doi.org/10.7202/706332ar

Aller au sommaire du numéro

Éditeur(s)

École de service social de l'Université Laval

ISSN

1708-1734 (numérique)

Découvrir la revue

Citer ce compte rendu

Lindsay, J. (1986). Compte rendu de [Réussir sa jeunesse - Réflexions du Congrès international sur la jeunesse, textes choisis et présentés par Simone Piuze, Montréal, Stanké, 1986, 162 pages.] Service social, 35(3), 488-489. https://doi.org/10.7202/706332ar d'utilisation que vous pouvez consulter en ligne.

https://apropos.erudit.org/fr/usagers/politique-dutilisation/ 
les intérêts professionnels et corporatistes comme obstacles premiers au changement des lois sur les drogues et à l'utilisation efficace des ressources pour toxicomanes.

Un second groupe de textes (Commission I) se rapporte aux réponses institutionnelles données aux jeunes aux prises avec des problèmes d'alcool et de drogue. Les uns touchent des ressources de réadaptation, les autres des actions judiciaires, et les derniers des interventions en milieu scolaire. C'est sûrement dans cette partie qu'un praticien trouvera le plus de matière pertinente.

La Commission II abordait la consommation de substances toxiques sous l'angle de la possibilité de choix et des facteurs qui peuvent influencer ceux-ci. On retrouve concrètement, dans ce troisième groupe de texte, outre une brève synthèse d'atelier sur l'influence des médias d'information sur les jeunes et les intervenants, deux présentations qui mettent en relation le comportement suicidaire et la toxicomanie.

La troisième Commission élargissait le débat par l'examen de quelques volets additionnels. Deux projets spécifiques et la possibilité d'un emploi sont présentés comme des alternatives à la consommation pouvant être proposées aux jeunes. Les autres ateliers ont touché l'implication communautaire bénévole, le rôle de la famille et l'entraide par les pairs.

Enfin, la Commission IV apportait un regard prospectif, et on retrouve des textes sur les valeurs des jeunes et sur leurs modèles d'identification.

Comme on peut s'y attendre, toutes les communications faites au colloque ne se retrouvent pas dans ce volume, et celles qui y sont varient en longueur et en qualité ; en ce sens, l'ouvrage est d'abord utile aux participants. Néanmoins, quelques textes sur l'intervention (dans les Commissions I et III) sont particulièrement intéressants. De plus, cet ouvrage a le mérite de faire mieux connaître l'Association des intervenants en toxicomanie du Québec.

École de service social,

Jocelyn LINDSAY

Université Laval.

Réussir sa jeunesse - Réflexions du Congrès international sur la jeunesse, textes choisis et présentés par Simone Piuze, Montréal, Stanké, 1986, 162 pages.

En novembre 1985, mille professionnels de toutes les régions du Canada participaient, à Montréal, à un congrès parrainé par les centres de jeunesse Shawbridge et l'Institut Philippe-Pinel, sous le thème "Jeunesse en devenir... se responsabiliser ". Madame Suzanne Piuze a choisi, parmi les cent trois conférences, celles qui lui semblaient les plus représentatives.

Le produit en est donc un volume contenant treize chapitres qui touchent autant de problématiques liées à la jeunesse. Les chapitres sont d'une longueur inégale (de 7 à 22 pages) et ont comme auteur la personne qui a fait la 
communication. On a conservé à l'écrit la forme initiale de la présentation verbale.

Compte tenu de la mission des centres de jeunesse Shawbridge et de l'Institut Philippe-Pinel, il est normal de retrouver une concentration de six textes sur le phénomène de la délinquance. Ils ont trait spécifiquement aux thèmes suivants : les jeunes psychopathes, l'approche thérapeutique des jeunes criminels, les enfants victimes de violence physique et sexuelle, le Tribunal de la jeunesse, les nouvelles législations, et la Loi sur les jeunes contrevenants.

Les autres textes élargissent le débat et permettent de considérer la jeunesse dans une perspective d'ensemble. Ainsi, deux chapitres abordent davantage le développement personnel de cette population (la sexualité chez l'adolescent, la responsabilité et les jeunes). Deux autres exploitent la dimension interactionnelle (effets du divorce chez l'enfant, impact des difficultés psychosociales sur la santé des adolescents). Le contexte organisationnel (autorité scolaire et droits des enfants), la question spirituelle (croyances et sectes religieuses) et l'aspect socioéconomique (chômage et jeunes) complètent ce tour d'horizon sur la jeunesse.

Du point de vue de la personne qui a choisi les textes: "Les éducateurs, parents ou amis des jeunes trouveront dans ce livre des conseils qui leur permettront de mieux aider les adolescents en difficulté. Mais mieux encore, les jeunes qui liront ce livre sentiront à quel point ils sont aimés et respectés ".

L'ouvrage constitue, à notre avis, une vulgarisation intéressante sur des thèmes souvent traités d'une façon moins accessible dans les revues scientifiques et professionnelles. Nous émettons également deux commentaires au plan de la forme : il aurait été souhaitable de regrouper les articles, comme nous l'avons fait plus haut, autour de thématiques plus larges; aussi, dans la table des matières, on aurait dû indiquer les noms des auteurs.

Ce livre peut donc intéresser plusieurs publics et constitue une bonne réflexion sur la jeunesse, avec une insistance particulière sur le thème de la délinquance.

École de service social,

Jocelyn LINDSAY

Université Laval.

Marie Gérin-Lajoie - De mère en fille, la cause des femmes, par Hélène Pelletier-Baillargeon, Montréal, Boréal Express, 1985, 383 pages.

Cet ouvrage est une biographie très élaborée de Marie Gérin-Lajoie, fondatrice de l'Institut Notre-Dame-du-Bon-Conseil, érigé canoniquement à Montréal le 26 avril 1923. D’autres figures féminines éminentes y prennent également place.

La rédactrice de ce livre est qualifiée à bon droit de "journaliste de grande trempe " par Christian Boutin, qui l'a interviewée en avril 1986 et dont le texte a paru dans le périodique Le troisième âge à la même date. 